\title{
Comparative Study of Bacterial Infection Prevalence Between Cirrhotic Patients With and Without Upper Gastrointestinal Bleeding
}

\author{
Delvone Almeida, Antônio A Lopes, \\ Rogerio Santos-Jesus, Igelmar Paes, \\ Helito Bittencourt and Raymundo Paraná
}

\author{
Federal University of Bahia, São Rafael Hospital, \\ Roberto Santos Hospital, Salvador, Bahia, Brazil
}

\begin{abstract}
Bacterial infection is a frequent complication in patients with chronic liver disease, mainly during the advanced stages. There is evidence that the main factors that contribute to a predisposition to infection in cirrhotic patients are related to hepatic failure with consequent immunodeficiency. Invasive procedures (diagnostic or therapeutic) can predispose to bacterial infections, and upper gastrointestinal bleeding (UGB) is considered a potentially important risk factor. A group of cirrhotic patients (child $B$ and $C$ Pugh groups ) were evaluated retrospectively by chart reviews regarding the prevalence of bacterial infection during hospitalization to determine whether UGB was a risk factor. An infection was considered present if a specific organ system was identified or if fever $\left(>3^{\circ} \mathrm{C}\right)$ persisted for more than 24 hours with associated leukocytosis. Spontaneous bacterial peritonitis was based on classical criteria. Eighty-nine patients were evaluated. Fourty-six patients presented with UGB, and 43 patients had no UGB (control). There were infections recorded in 25/46 (54\%) patients with UGB, and $15 / 43(35 \%)$ in those without $U G B(p=0.065)$. The ratio of the number of infections/admitted patients, was significantly larger in the group with UGB $(0.78 \pm 0.89$ vs. $0.39 \pm$ $0.62 ; p=0.028$ ) since patients had more than one infection. In the UGB group compared to non UGB group, ascites was more frequent $(67 \% \mathrm{vs} .42 \% ; p=0.027)$; they were more likely to have undergone endoscopic procedures $(p<0.001)$ and the mean \pm SD for platelets count was smaller $(96,114 \pm$ $57,563$ vs. $145,674 \pm 104,083 ; p=0.007)$. The results show that UGB is an important contribution to bacterial infection among Child $B$ and $C$ cirrhotic patients.

Key Words: Cirrhosis, upper gastrointestinal bleeding, bacterial infections, spontaneous bacterial peritonitis.
\end{abstract}

Bacterial infection is a common complication in patients with cirrhosis $[1,2]$. The cirrhotic patients with gastrointestinal bleeding frequently develop bacterial infections, above all from Gram negative bacilli of enteric origin [3]. Experimental studies in animals have shown that enterobacteria can translocate the epithelial mucosa into the lamina propria and then reach the mesenteric lymph nodes and the circulatory system [4].

Received on 17 February 2001; revised 18 April 2001.

Address for correspondence: Dr. Delvone Almeida, Avenida Juracy Magalhães Jr. 2096, sala 510, Salvador-BA, 41920.000 Brazil. Phone::+55712357048; Fax:+55713534980.

E-mail:delvone@zaz.com.br

The Brazilian Journal of Infectious Diseases 2001;5(3):136-142 (C) 2001 by The Brazilian Journal of Infectious Diseases and Contexto Publishing. All rights reserved. $1413-8670$
Among the factors that can contribute to infections in cirrhotic patients are those triggered by the disease itself, such as malnutrition and upper gastrointestinal bleeding (UGB). Diagnostic and therapeutic procedures also contribute to infection due to rupture of the natural barriers.

Some studies have described the distribution of the most frequent types of infection and their severity $[5,6]$. Few studies, however, have tried to asses whether the frequency and severity of infection is related to the presence of UGB [7, 8], In addition, studies focused on patients with a greater loss of hepatic functional reserves (Child B and C) are still scarce. The objective of this study was to compare the prevalence of bacterial infection between Child $B$ and $C$ cirrhotic patients with and without UGB. 


\section{Materials and Methods}

\section{Patient selection}

Eighty-nine hospitalized patients were included in this study after retrospective chart review. One group with UGB $(n=46)$ were identified and another one without UGB $(n=43)$ were identified. All patients had an established diagnosis of chronic liver disease and were admitted to the São Rafael Hospital and to the Roberto Santos General Hospital, Salvador, Bahia, during the period from September, 1991, to December, 1999. The data were extracted from medical records, identifying the patients with infections in the 2 groups. The following exclusion criteria were used: 1) symptoms of infection upon admission; 2) death within 12 hours of admission; 3) surgery within 24 hours after admission; 4) antibiotic use one week before admission; 5) Child A by Child-Pügh criteria; 6) hospital stay for less than three days; 7) presence of cancer.

The diagnosis of hepatic cirrhosis was based on clinical, biochemical, echographic findings and/or data from the hepatic biopsy. The Child-Pügh classification was used to determine the liver function stage.

Attributable cause of the hepatic disease was defined based on medical records. Patients without a confirmed diagnosis at the time of inclusion in the study - absence of specific diagnostic exams or lack of biopsy - were considered undetermined.

\section{Criteria for diagnosis of infection}

Patients without inner abdominal sources of infection, who had a neutrophil count from the ascitic liquid $\geq 250 / \mathrm{mm}^{3}$, were diagnosed as spontaneous bacterial peritonitis (SBP) carriers, independent of a culture result. Secondary bacterial peritonitis was considered when there was an internal or paraabdominal infection source. The diagnosis of urinary tract infection (UTI) was based on clinical and laboratory data (dysuria, with urinary count $>15$ leukocytes $/ \mathrm{mm}^{3}$ and/ or positive urine culture $>100,000$ colonies/ml). Respiratory infections were confirmed by clinical, radiological or bacteriological data. Other infections were confirmed by specific methods, requested according to the patient clinical data. Patients without an apparent source of infection, but with fever $\left(>38^{\circ} \mathrm{C}\right)$ for more than 24 hours, associated with leukocytosis and neutrophilia, were also considered as having bacterial infection. The diagnosis of sepsis took into account the combination of the following findings: fever $\left(>38^{\circ} \mathrm{C}\right)$ or hypothermia $\left(<36^{\circ} \mathrm{C}\right)$, tachycardia (>90 bpm/min), tachypnea (>20 events/min), mental deterioration, hypoxemia ( $<70 \mathrm{mmHg})$, metabolic acidosis, and oliguria (urinary output $<30 \mathrm{ml} / \mathrm{h}$ ).

\section{Statistical analysis}

Prevalence was used as the frequence measure of infection episodes. The $95 \%$ confidence interval (CI) was used to describe the precision of the prevalence ratio (PR). The Student T test, the Chi-square test (or the Fisher exact test) and the Mann-Whitney test were used to assess differences in means and proportions. All statistical tests were two-sided. A difference was considered statistically significant when $\mathrm{p}$ was lower than $0.05(5 \%)$. The software "Statistical Package for Social Science", SPSS (Norusis, 1993a, 1993b) was used for the analysis.

\section{Results}

\section{Patient characteristics}

Table 1 displays the characteristics of patients with and without UGB, by gender, age, duration of hospitalization and disease stage (according to the Child Pügh-Classification). There was a predominance of males in the 2 groups ( $84 \%$ vs. $86 \%$, in the group with and without UGB, respectively). The mean \pm SD of age was $51 \pm 11$ years in patients with UGB and $57 \pm$ 10 years in patients without UGB $(56.7 \pm 9.7)$. The median in both groups was 58 years. The duration of hospitalization was not $(17.8 \pm 2.2$ vs. $14.4 \pm 1.3$ days) significantly different. The proportion of patients in stages $\mathrm{C}$ (Child-Pügh Classification) was similar between patients with $(48 \% ; 22 / 46)$ and without UGB $(51 \% ; 22 / 43)$. 
Table 1. Patient characteristics with regard to gender, age, time of hospitalization and disease stage according to the Child-Pügh classification

\begin{tabular}{lllc}
\hline & \multicolumn{3}{c}{ Upper Gastrointestinal Bleeding } \\
\cline { 2 - 4 } & Yes $(\mathbf{n}=\mathbf{4 6})$ & $\mathbf{N}^{\mathbf{0}}(\mathbf{n}=\mathbf{4 3})$ & p value \\
\cline { 2 - 4 }$\%$ of males & $84.8 \%(39)$ & $86 \%(37)$ & 1 \\
Age (mean \pm SD) & $51.4 \pm 11.4$ & $56.7 \pm 9.7$ & 0.02 \\
Age (median) & 52 & 51.5 & 0.26 \\
Hosp (mean \pm SD) & $17.8 \pm 15.0$ & $14.4 \pm 8.9$ & 0.91 \\
$\%$ Child C & $47.8 \%(22)$ & $51.2 \%(22)$ & \\
SD: standard deviation; Hosp:duration of hospitalization in days; \% Child C: \% of Child C stage according \\
to Child-Pügh classification.
\end{tabular}

Table 2. Patients' characteristics according to disease etiology

\begin{tabular}{|c|c|c|c|c|}
\hline \multirow[b]{2}{*}{ Etiology } & & \multicolumn{3}{|c|}{ Upper Gastrointestinal Bleeding } \\
\hline & Yes $(n=46)$ & $N^{o}(n=43)$ & Total & p value \\
\hline $\mathrm{HBV}$ & $2(4.3 \%)$ & $4 \quad(9.3 \%)$ & $6 \quad(6.7 \%)$ & 0.56 \\
\hline $\mathrm{HCV}$ & $4 \quad(8.7 \%)$ & $6(14 \%)$ & $10(11.2 \%)$ & \\
\hline SBC & $1 \quad(2.2 \%)$ & $1 \quad(2.3 \%)$ & $2(2.2 \%)$ & \\
\hline UND & $7(15.2 \%)$ & $8(18.6 \%)$ & $15(16.9 \%)$ & \\
\hline Alc & $26(56.5 \%)$ & $23(53.5 \%)$ & $49(55.1 \%)$ & \\
\hline Alc/HBV/HCV & $1 \quad(2.2 \%)$ & $1 \quad(1.1 \%)$ & & \\
\hline Alc/HCV & $5(10.9 \%)$ & $1 \quad(2.3 \%)$ & $6 \quad(6.7 \%)$ & \\
\hline
\end{tabular}

HBV: virus B; HCV: virus C; SBC: secondary biliar cirrhosis; UND: undetermined; Alc: alcohol.

Table 3. Laboratory characteristics according to the presence or absence of UGB

\begin{tabular}{lllc}
\hline & \multicolumn{3}{c}{ Upper Gastrointestinal Bleeding } \\
\cline { 2 - 4 } & Yes $(\mathbf{n}=\mathbf{4 6})$ & $\mathbf{N}^{\mathbf{o}}(\mathbf{n}=\mathbf{4 3})$ & p value \\
\cline { 2 - 4 } Alb $($ mean \pm SD) & $2.79 \mathrm{mg} \% \pm 0.73$ & $2.87 \mathrm{mg} \% \pm 0.73$ & 0.587 \\
PT sec $($ mean \pm SD) & $50,47 \pm 16.0$ & $54.58 \pm 16.9$ & 0.243 \\
Leuco $($ mean \pm SD) & $11,091 \pm 11,595$ & $8,058 \pm 11,101$ & 0.21 \\
Plat $($ mean \pm SD) & $96,114 \pm 57,563$ & $145,674 \pm 104,083$ & 0.007 \\
\hline
\end{tabular}

Alb: albumin; PT: Prothrombin time in seconds; Leuko: leucocyte count; Plat: platelets. 
Table 4. Distribution of the infections by group

\begin{tabular}{llrrrl}
\hline & \multicolumn{5}{c}{ Upper Gastrointestinal Bleeding } \\
\cline { 2 - 6 } Infections & Yes $(\mathbf{n}=\mathbf{4 6})$ & No $(\mathbf{n}=\mathbf{4 3})$ & \multicolumn{1}{c}{ Total } & p value & PR $($ IC95\%) \\
\hline Perito & $19.6 \%(9 / 46)$ & $7.0 \%(3 / 43)$ & $13.5 \%(12 / 89)$ & 0.15 & $2.8(0.8-9.6)$ \\
Pneu & $13 \%(6 / 46)$ & $2.3 \%(1 / 43)$ & $7.9 \%(7 / 89)$ & 0.11 & $5.6(0.7-44.7)$ \\
Sepsis & $13.3 \%(6 / 46)$ & $2.3 \%(1 / 43)$ & $8.0 \%(7 / 89)$ & 0.11 & $5.7(0.71-45.6)$ \\
ITU & $10.9 \%(5 / 46)$ & $9.3 \%(4 / 43)$ & $10.1 \%(9 / 89)$ & & 1.0 \\
Others & $22 \%(11 / 46)$ & $18.7 \%(8 / 43)$ & $40.7 \%(19 / 89)$ & 0.4 & 1.2 \\
\hline
\end{tabular}

Perito: peritonitis; Pneu: pneumonia; UTI: urinary tract infection; Others: Others infections (bacteremia, colangitis, sinusitis, erysipela, abdominal cellulite, endocarditis and infectious diarrhea.

Figure 1. Comparative study of bacterial infection prevalence among cirrhotic patients with and without upper digestive bleeding

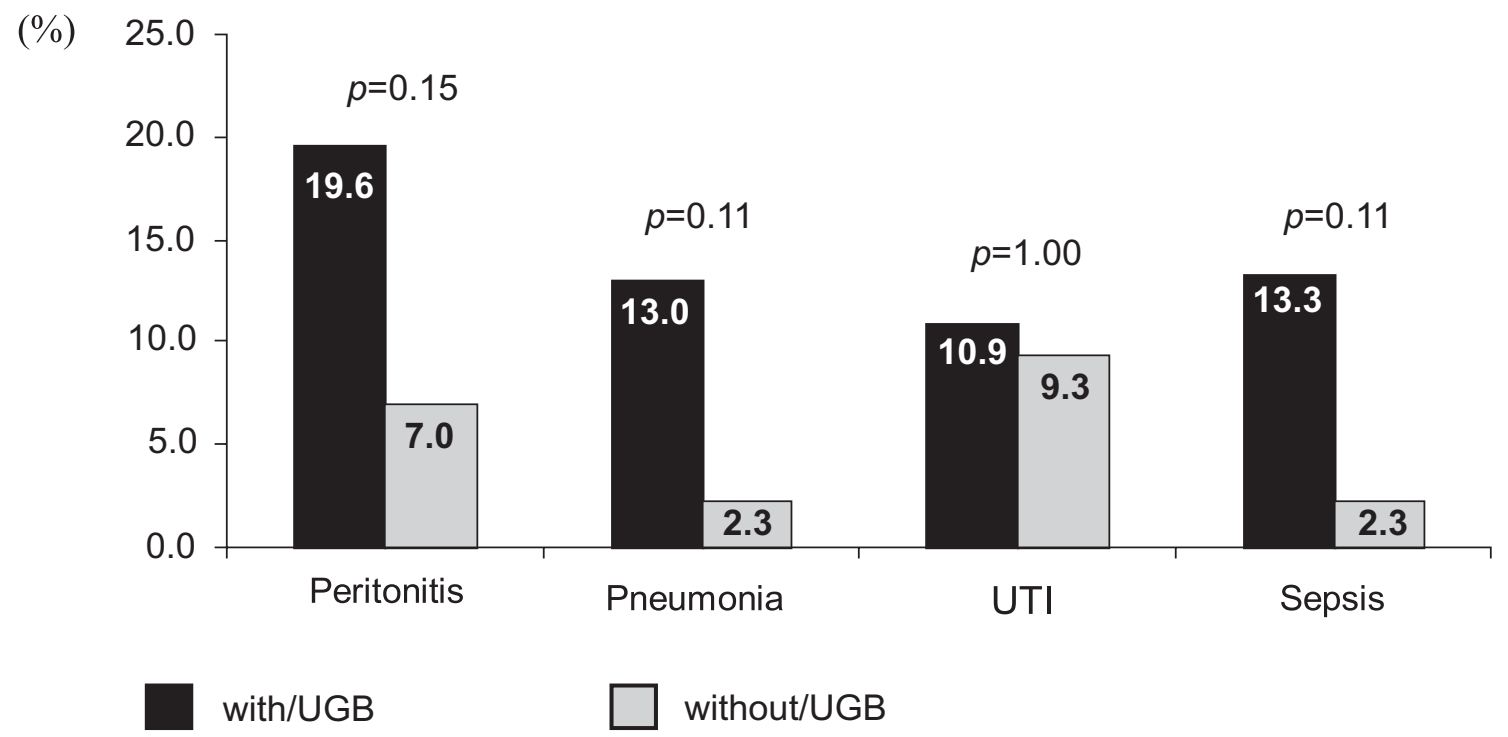


Table 2 shows the distribution percentage of attributable causes of hepatic disease between patients with and without UGB. In the majority of the patients $(55.1 \%)$, the hepatic disease was attributed to alcohol, with similar frequency $(\mathrm{p}=0.56)$ between the groups with $(56.5 \%$; 26/46) and without UGB (53.5\%; 23/43).

Table 3 presents the laboratory profile of the patients according to the UGB. There was no statistically significant difference between the groups regarding the serum levels of aminotransferases, bilirubin, albumin and prothrombin time. By contrast, the platelet count was significantly lower $(96,114 \pm 8,678$ vs. $145,674 \pm$ $15,873)$ in the group with UGB $(\mathrm{p}=0.007)$.

The proportion of patients that indicated alcohol use in the period immediately prior to admittance was 1.8 times greater $(\mathrm{PR}=1.8 ; 95 \% \mathrm{CI}=0.9-3.4 ; \mathrm{p}=0.094)$ in the group with UGB $(43.2 \%$; 19/44) than without UGB $(23.8 \%$; 10/42). The data on alcohol intake was missing in 3 patient files. The case-fatality rate was approximately 1.9 times greater in patients with $(22.2 \%$; $10 / 46$ ) than in those without $(9.3 \% ; 4 / 43)$ UGB $(\mathrm{PR}=1.9 ; 95 \% \mathrm{CI}=0.8-7.0 ; \mathrm{p}=0.17)$.

Characteristics of the sample according to the probable risk factors for infection

The frequency of ascites was higher in patients with $\operatorname{UGB}(67.4 \%$; $31 / 46)$ than in patients without $(41.9 \%$; $18 / 43)$ UGB $(p=0.027)$. The frequency of granulocytopenia (leukocyte count lower than 2,000) was similar $(\mathrm{p}=1)$ between the groups with $(5 / 46 ; 10.9 \%)$ and without UGB $(5 / 43 ; 11.6 \%)$. Diabetes mellitus was diagnosed in 1 patient in the group with UGB and in 4 patients in the group without UGB $(\mathrm{p}=0.31)$.

General aspects of the two groups with regard to infections

The frequency of infections was greater among patients with UGB $(54 \% ; 25 / 46)$ than in those without UGB $(35 \% ; 15 / 43)$. The association between UGB and infection was at the bordeline of significance $(p=0.065)$. The evaluation of the average number of bacterial infections per patient in each group reveals that there is a difference in the analysis: mean number of infections \pm Standard Deviation: $0.78 \pm 0.89$ vs. $0.39 \pm 0.62$. It should be taken into consideration that a patient sometimes presented more than 1 infection during hospitalization. The statistical analysis was significant $(\mathrm{p}=0.028)$.

Figure 1 displays the distribution of peritonitis, pneumonia, UTI, and sepsis in the 2 groups. The infections are presented by order of importance and frequency.

In the group with UGB, cytologic and bacteriologic exams of the ascitic fluid were not performed in 4 patients. Three of them progressed without a diagnosed infection, and 1 presented fever, and neutrophilia and was treated for SBP. This patient was included as having bacteremia of unknown source. A case of secondary bacterial peritonitis was identified in the group with UGB. In the group without UGB, 3 patients did not undergo paracentese, 1 remained without symptoms of infection; 1 patient was treated for sinusitis, and 1 patient was treated for urinary tract infection.

Considering the available data, the frequency of peritonitis was $19.6 \%$ (9/46) in the group with UGB and $7 \%(3 / 43)$ in the group without UGB $(\mathrm{PR}=2.8$; 95\% CI=0.8-9.6; $\mathrm{p}=0.15$ ).

Pneumonia prevalence was greater in the group with UGB (13\%; 6/46 vs. $2.3 \%$; 1/42) than in the group without UGB ( $\mathrm{PR}=5.6$; 95\% $\mathrm{CI}=0.7-44.7 ; \mathrm{p}=0.11)$. Sepsis was more frequentely diagnosed in the group with UGB (13.3\%; $6 / 46$ vs. $2.3 \% ; 1 / 43 ; p=0.11)$ than in group without $\mathrm{UGB}(\mathrm{RP}=5.7 ; 95 \% \mathrm{CI}=0.71-45.7)$. UTI prevalence was similar between the groups (10.9\%; 5/46 vs. $9.3 \% ; 4 / 43 ; \mathrm{p}=1$ ).

Less frequent bacterial infections (bacteremia, colangitis, sinusitis, erysipela, abdominal cellulite, endocarditis and infectious diarrhea) were found in a similar proportion $(\mathrm{p}=0.4)$ in the two groups $(22 \%$; 11/46; vs. 18.7\%; 8/43).

The result of the hemocultures revealed that the bacteria most commonly isolated was E. coli (8 cases), followed by S. pneumoniae and enterococus (3 cases each). Other microorganisms ( $S$. aureus, Pseudomonas sp, Klebsiella) were also isolated in different patients. 


\section{Discussion}

The results of the present study are consistent with previous investigations, showing a relatively high prevalence of bacterial infections in hospitalized cirrhotic patients. It is important to note that patients hospitalized with a diagnosis of infection were excluded from the study. It is not possible to rule out the possibility, however, that some patients had asymptomatic infection at hospital admission.

Although several studies have addressed the question of bacterial infection in cirrhotic patients [5-7], few of them compared subjects with and without UGB [7]. In fact, the majority of studies describe the frequency of infection without specifying the occurrence of this specific clinical condition. Other studies limit the description to infection incidence in the patients that underwent antibiotic prophylaxis during UGB episodes, compared with others that did not use systemic antibiotic prophylaxis [9-11] and/or selective intestinal decontamination [12-14], with oral antibiotics.

In a meta-analysis study, Bernard, et al. [15], gathered 5 random clinical trials from 1985 to 1989 [9-14]. The result was favorable for antibiotic prophylaxis in cirrhotic patients with UGB, for reducing infection incidence, as well as increasing survival.

Another peculiar aspect of the present study was the focus on patients with more advanced disease stages (Child B and C). These patients are more susceptible to infection by the loss of hepatic function, as well as presenting a higher probability of undergoing invasive procedures in a hospital setting [16].

The lower mean age in the group with UGB could be related to the fact that almost twice as many UGB patients continued to consume alcohol until the date of admission. This fact could explain the earlier disease evolution in this group. Patients mean age in the present study was similar to that described by other investigators $[17,18]$.

A similar distribution of patients by disease stage was observed between the groups. Thus, a higher frequency of infection in patients with UGB cannot be fully explained by a lower hepatic function.
The patients both with and without UGB were similar regarding the serum albumin level and prothrombin time. Even though leukocyte count was similar between the groups, platelet count was significantly lower in the group with UGB. Platelet disorders have been found in cirrhotic patients that also present a low leukocyte count, sometimes conditoned to hypersplenism. Isolated platelet disorder may be related to viral diseases, however the pathogenic mechanism is still not understood. Andreu, et al. [19], associated a platelet count $<116,000 / \mathrm{mm}^{3}$ to a higher risk of SBP development in these patients, aside from other variables such as decrease of serum albumin and prolonged prothrombin time, denoting the close relationship with the loss of hepatic functional reserves. In the current study, the more accentuated platelet disorders in the group with UGB can also be explained by the consumption during the hemorrhage episodes or consequent to the chronic disseminated intravascular coagulation caused by severe hepatic failure.

We observed granulocytopenia in $11.2 \%$ of the patients. Apparentely, a higher tendency for infection cannot be attributed to leukopenia.

Similar to other studies [20,21], SBP was the most prevalent infection in our patients, follwed by UTI and pneumonia. Ascites was more frequent in the group with UGB, probably facilitating SBP development, a common infectious complication in these patients. Intestinal bacterial translocation also appears to be facilitated by UGB [22].

In general, we observed a higher frequency of infection among the UGB patient's group. The fact that statistical significance was not attained may be related to the relatively small number of patients in the groups. It is also possible that infection episodes were not recorded for all patients. Consistent with this possibility, UTI was found in just $10 \%$ of the patients, while the reported incidence in cirrhotic patients is around $25 \%$. This may suggest missed diagnoses.

As expected, a larger number of sepsis cases were described among the UGB patients. No data is given whether death was due to bleeding or infection. This is needed before any conclusion can be made about the effect of infection on mortality. 
In conclusion, the present study shows a high prevalence of bacterial infections in patients with UGB. As in with other studies, there was an association between UGB and ascitic development that may explain the high prevalence of SBP in these patients. UGB patient mortality was higher, although without statistical significance.

The patients with UGB presented accentuated platelet disorders, probably from increased consumption during the natural processes of homeostasis.

Reducing the incidence of complications in cirrhotic patients is one of the important objectives in current gastroenterology practice. Early diagnosis and effective prevention measures constitute current challenges for the reduction of mortality and morbidity in these patients. The use of prophylatic antibiotic therapy has been defended and can be benefical, however it is necessary to establish protocols, defining the treatment and prophylaxis strategies (systemic antibiotic therapy or selective intestinal decontamination), as well as the ideal clinical conditions for use.

\section{References}

1. Diaz Curiel M., Fernandez Guerrero M.L., Suarez Fernandez C. Infecciones en la cirrosis hepática. Ver Clin Esp 1984; $172: 241-50$.

2. Navasa M., Fernández J., Rodés J. Bacterial Infections in liver cirrhosis. Ital J Gastroenterol Hepatol 1999;31:7 616-25.

3. Morencos F., Castaño G., Ramos L., et al. Small bowel bacterial overgrowth in patients with alcoholic cirrhosis. Dig Dis Sci 1995;40:1252-6.

4. Alexander J.W., Boyce S.T., BabcocK G.F., et al. The process of microbial translocation. Ann Surg 1990;212:496-512.

5. Caly W.R., Strauss E. A prospective study of bacterial infections in patients with cirrhosis. J Hepatol 1993; 18:353-8.

6. Toledo C., Flores C., Saénz M., et al. Infecciones Bacterianas en la Cirrosis Hepática. Ver Med Chil 1994;122:788-94.

7. Deschênes M., Villeneuve J.P. Risk factors for the development of bacterial infections in hospitalized patients with cirrhosis. Am J Gastroenterol 1999; $94: 2193-7$.

8. Bernard B., Cadranel J.F., Valla D., et al. Prognostic significance of bacterial infection in bleeding cirrhotic patients: A Prospective Study. Gastroenterology 1995; $108: 1828-34$
9. Blaise M., Pateron D., Trinchet J.C., et al. Systemic antibiotic therapy prevents bacterial infections in cirrhotic patients with gastrointestinal hemorrhage. Hepatology 1994;20:34-8

10. Pawels A., Mostefa-Kara N., Debenes B., et al. Systemic antibiotic prophylaxis after gastrointestinal hemorrhage in cirrhotic patients with a high risk of infection. Hepatology 1996;24:802-6.

11. Felisart J., Rimola A., Arroyo V., et al. Cefotaxime is more effective than ampicillin in cirrhotics with severe infections. Hepatology 1985;5:457-62.

12. Soriano G., Guarner C., Tomás A., et al. Norfloxacin prevents bacterial infections in cirrhotics with gastrointestinal hemorrhage. Gastroenterology 1992; 103:1267-72

13. Hsieh W.J., Lin H.C., Hwang S.J., et al. The effect of ciprofloxacin in the prevention of bacterial infection in patients with cirrhosis after upper gastrointestinal bleeding. Am J Gastroenterol 1998;93:962-6.

14. Rimola A., Bory F., Teres J., et al. Oral, nonabsorbable antibiotics prevent infection in cirrhotics with gastrointestinal hemorrhage. Hepatology 1985;5:463-7.

15. Bernard B., Grangé J.D., Khac E., et al. Antibiotic prophylaxis for the prevention of bacterial infections in cirrhotic patients with gastrointestinal bleeding: A Meta-Analysis. Hepatology 1999;29:1655-61.

16. Pawels A., Chami N., Guivarch P., et al. Facteurs prédictfs des.infections survenant au décours des hémorragies digestives hautes du cirrhotique. Gastroenterol Clin Biol 1990; $14: 219$ A.

17. Barnes P., Arevalo C., Chan L., et al T. A prospective evaluation of bacteremic patients with chronic liver disease. Hepatology 1988;8:1099-103.

18. Kuo C., Changchien C.S., Yang C.Y., et al. Bacteremia in patients with cirrhosis of the liver. Liver 1991;11:334-9.

19. Andreu M., Sola R., Serra A., et al. Risk factors for spontaneous bacterial peritonitis in cirrhotic Patients with ascitis. Gastroenterology 1993;104:1133-8.

20. Navasa M., Rimola A., Rodés J. Bacterial infections. Seminars in liver disease 1997; 17:323-33.

21. Ricart E., Soriano G., Novella M., et al. Amoxicillinclavulanic acid versus cefotaxime in the therapy of bacterial infections in cirrhotic patients. J Hepatology 2000;32:596-602.

22. Garcia-Tsao G., Allbillos A., Barden G.E., et al. Bacterial translocation in acute and chronic portal hypertension. Hepatology 1993;17:1081-5. 